\title{
EDITORIAL
}

\section{The patient connexion...}

\section{Sanjay N Jain}

Editor-in-Chief, The Indian Journal of Radiology and Imaging, Department of Radiology, Prince Aly Khan Hospital, Mazagaon, Mumbai, Maharashtra, India. E-mail: Editor@ijri.org

Dear colleagues,

As in the last year of this term, I begin by thanking you for the immense support offered to me in helping bring out timely issues, in pursuit of taking our journal to a new high. I am very happy to state that we have reached a stage wherein, we have more than sufficient material for the entire set of issues for 2015.

In this issue, we feature on the concept of the radiologist interacting with patients, to help them understand the findings; though, this is not much in vogue in our country, a seemingly established practice in the west. Over and above the findings inferred by the radiologist, he or she is now discussing with the patient, directly, to give them a direct insight into the reports; a personal touch. Given a chance, patients appreciate the opportunity to meet the radiologist, in pursuit of knowing the findings in their radiology report. ${ }^{[1]}$

Given the fact that patients come for various imaging modalities to an institute or center, few of them have a direct interaction with the reporting doctor, especially true for ultrasonography, mammography and interventional radiology. The rest of them have an investigation done and are politely told to consult the referring physician for further inputs on the report. This seemingly involuntary

\begin{tabular}{|l|l|}
\hline \multicolumn{2}{|c|}{ Access this article online } \\
\hline Quick Response Code: & \\
\hline & Website: \\
\hline & www.ijri.org \\
\cline { 2 - 3 } & DOI: \\
\hline
\end{tabular}

action does keep the patient at times in a lurch, pondering over many aspects of the report and the likely shock in case of an unusual finding such as cancer. Nevertheless, many referring physicians do seem to have taken a virtual stand on this but are not averse to the radiologist talking to the patient about their report.

This has come into being based on the pilot study conducted by researchers from Massachusetts, General Hospital, recently. The study was outlined by Dr. Gary Choy, who stated that patients have appreciated the role of the radiologist, outside the room, as much inside. He further said that both the patients and their referring physicians found it very helpful. ${ }^{[2]}$

The seemingly virtual don't-talk-to-me trajectory needs an orbital change perhaps. Patients do have a natural curiosity about their report, and if the radiologist does remove those few seconds for conversing with them, it would go a long way in building up the rapport. ${ }^{[3]}$ Surely, not everyone but those few who do want to know a bit more than that piece of paper constituting the report. A challenge which the radiologist can circumvent and add value to patient care.

\section{References}

1. Available from: http://www.acr.org/News-Publications/News/ News-Articles/2014/ACR-Bulletin/201408-One-Specialty. [Last accessed on 2015 Jan 20].

2. Available from: $\mathrm{http}: / / \mathrm{www} \cdot \mathrm{auntminnie.com} /$ index.aspx? $\mathrm{sec}=\mathrm{sup} \&$ sub=pac\&pag=dis\&itemId=107499. [Last accessed on 2015 Jan 20].

3. Available from: http://www.radiologytoday.net/archive/rt0113p22. shtml. [Last accessed on 2015 Jan 20].

Cite this article as: Jain SN. The patient connexion.... Indian J Radiol Imaging 2015;25:1. 